\title{
Day-of-the-Week Effect and Investors' Psychological Mood Testing in a Highly Mispriced Capital Market
}

\author{
Rizky Luxianto ${ }^{1,}$ Usman Arief $^{2^{*}}$ and Muhammad Budi Prasetyo ${ }^{1}$ \\ ${ }^{1}$ Department of Management, Faculty of Economics and Business, Universitas Indonesia, Depok, \\ 16424, Indonesia \\ ${ }^{2}$ Department of Management, Faculty of Economics and Business, Universitas Gadjah Mada, \\ Yogyakarta, 55281, Indonesia
}

\begin{abstract}
Research Aims: This research examines investors' psychological moods which cause day-of-the-week anomalies in highly mispriced stock markets. Design/methodology/approach: We use a sample from the Indonesian capital market as, in the Asian region, this country is considered to have a highly mispriced capital market. We decompose the stock price index in Indonesia into speculative, less speculative, and nonspeculative indexes. We employ the mean and variance regressions to control the heteroscedasticity and serial correlation. Novelties: Our novelties are two fold. We postulate a method to decompose stock price indexes in Indonesia (the JKSE, LQ 45, and Kompas 100) into speculative, less speculative, and non-speculative indexes. Secondly, we estimate the mean and variance levels simultaneously to get a robust estimation result of the anomaly. Research Findings: We empirically find that the behavior mood hypothesis is supported only during normal periods, when investors tend to be irrational and use their good mood to trade on speculative stocks on a Wednesday and sell them on Monday. In other periods, rationality and psychological effects play a role with Indonesian investors, when their mood is good they are more active in trading less speculative stocks, to avoid higher risks and earn higher returns from those less speculative and non-speculative stocks.
\end{abstract}

ARTICLE INFO

Article information:

Received in 21 February 2020.

Received in revised form 26 April 2020.

Received in revised form 27 May 2020.

Accepted 3 June 2020.

Keywords:

Indonesia, day-of-the week, anomaly, decomposition, psychology, mood, behavioral finance

JEL Code:

G12, G15, G40, F30

\footnotetext{
* Corresponding Author at Department of Management, Faculty of Economics and Business, Universitas Gadjah Mada, Yogyakarta, 55281, Indonesia.

E-mail address: usman.arief@ugm.ac.id
}

ISSN 2085-8272 (print), ISSN 2338-5847 (online)

http://journal.ugm.ac.id/jieb 


\section{INTRODUCTION}

The efficient market hypothesis (EMH) proposed by Fama (1970) stated that all the available information is incorporated into a stock's price, and no one can beat the market from taking advantage of that kind of information. Nevertheless, in a capital market, there are several empirical findings which reveal several anomalies, namely the calendar effect, size effect, low book value, and winner-loser. These findings argue that capital markets are not fully efficient since the theoretical frameworks cannot clearly explain the existence of anomalies.

One of the well-known and most research anomalies is the calendar effect. This anomaly explains that the high and the low returns in a capital market have a seasonality pattern. As a consequence, investors can beat the market using a simple strategy of buying at a low price and selling at a high price, or buying at a high price and selling at a higher price. Some calendar effects that are often examined by researchers are time-of-the-day effects, day-of-the-week effects, week-of-the-month effects, and monthof-the-year effects. The first study of these calendar effects is the day-of-the-week effect, by Kelly (1930), which revealed that the United States stock markets' returns are relatively lower on Mondays and then at their highest on Fridays.

In general, the day-of-the-week phenomenon is a tendency for stock returns to be relatively higher at certain times (e.g., Friday) and lower at other times (e.g., Monday). With this anomaly, investors can easily get an abnormal return by buying on Monday and then selling on Friday. Birru (2018) mentioned three hypotheses that cause day-of-the-week effects, including the possibility that institutional traders trade at a particular time so that the return on that day is higher. Second, there is a tendency for news releases at certain times, causing abnormal returns at that time. The last argument is related to the investors' psychology and moods. This hypothesis says that the mood of traders tends to increase from Thursday to Friday and then decrease on Monday. Hence, traders tend to evaluate prospects optimally when they are in a good mood, rather than in a bad mood.

Some empirical findings (Wright \& Bower, 1992; Bagozzi et al., 1999) supported the investor psychology hypothesis. They argued that people who are in a good mood tend to evaluate good stimuli such as consumer goods, life satisfaction, or past life experiences more positively than when they are in a bad mood. This happens with investors too, if they are in a good mood at the end of the week, they tend to buy stocks since they see the prospective value of a stock increasing in the future.

A recent study byChiah and Zhong (2019) examined the day-of-the-week effect internationally. They useddata from 24 developed stock market countries around the world. Their finding is quite remarkable, since positive global returns on Friday, and negative returns on Monday are a manifestation of the mispricing effect, which is driven by investor sentiment. They also reveal that the optimistic investors tend to buy speculative stocks on Fridays, and vice versa, the pessimist investors tend to sell (or avoid trading) on Mondays. They concluded that psychological investors lead the day-of-the-week effect around the world. Another study that supports Chiah and Zhong (2019) is by Ali et al. (2018) which revealed the short-term reversal seen on Mondays was due to investor sentiment.

Speculative stocks are stocks that are traded in small volumes, they are volatile, unprofitable, non-dividend paying, lottery-like, potentially close to distress and have extreme growth; stocks like these are difficult to judge properly (Birru, 2018; Asness et al., 2018; Chiang \& 
Zhang, 2019). Furthermore, Chiah and Zhong (2019), and Ali et al. (2018) have empirically found that investors tend to be optimistic about the futures of speculative stocks on a Friday, rather than on other days.

This study is motivated by Chiang and Zhong (2019) who used a developed countries dataset. The primary purpose of this paper is to investigate the day-of-the-week phenomenon in developing countries such as Indonesia. Compared to previous studies, we found gaps in the research: First of all, and to the best of our knowledge, this is the first study to investigate the hypothesis of investors' moods in emerging markets. Secondly, the previous studies which examined the hypothesis only used one major stock index for each country. We divided the Jakarta Stock Exchange Composite index (JKSE), as the stock market in Indonesia, into three indexes consisting of speculative, less speculative, and non-speculative. Since the effect of the investors' moods will be different for each index, we consider that our findings will contribute to the existing literature.

We chose to use data from the Indonesian stock market when we became aware of the uniqueness of this index. This decision was based on research by Stambaugh, Yu, and Yuan (2015)and Jacobs (2016), who all revealed that the Indonesian stock market had a greater mispricing condition compared to other markets in Southeast Asia. This mispricing condition meant the existing information was not incorporated perfectly in the stock prices. Secondly, the proportion of foreign investors in Indonesia was greater, at around $50.64 \%$, compared to domestic investors. This causes the majority of the stock trading to be dominated by foreign investors who have some preferences and characteristics in trading. To re-examine the findings from Chiang and Zhong (2019), we stocks, less speculative stocks, and nonspeculative stocks. According to Birru (2018), Asness et al., (2018), and Chiang \& Zhang (2019) the day-of-the-week effect was more significant in a speculative index rather than a less speculative index, or a non-speculative index. Hence, in this paper, we seek to answer the following questions:

1. Is there a day-of-the-week effect anomaly in three indexes in Indonesia?

2. Is the day-of-the-week effect more significant in a speculative index instead of less or non-speculative indexes?

Our novelties from this study for the asset pricing literature are two-fold. We postulate a method to decompose stock price indexes in Indonesia (JKSE, LQ 45, and Kompas 100) into speculative, less speculative, and non-speculative indexes. Conventionally, to identify the speculative stocks, we would need to list all of the speculative stocks manually and create a value-weighted index, as suggested by Chiah and Zhong (2019). This work requires a lot of effort to identify the speculative and nonspeculative stocks. Hence, to make the work more efficient, we use the characteristics of indexes in Indonesia based on the performance of the companies. We believe that our method is more efficient for creating the speculative index, compared to the previous research papers. Secondly, we test the anomaly of the day-of-theweek effect at the mean and variance levels simultaneously, and our results will be robust for time-series stylized facts (heteroscedasticity and serial correlation).

The rest of this study proceeds as follows. Section 2 describes the literature review. Section 3 explains the methodology, Section 4 presents the empirical findings, and Section 5 offers the conclusion. 


\section{LITERATURE REVIEW}

\section{Day-of-The-Week-Effect}

One theory dealing with financial markets that has been the subject of much research is the efficient market hypothesis (EMH). Fama (1965) stated that a market would move based on every new additional piece of information. In addition, the price of an asset or stock on a market already reflected the historical information related to it. The further implication is that no investor will be able to gain greater returns than the market, using the information that is already available.

Given this proposition, many researchers had challenged the EMH by identifying the source of abnormal returns that can beat the market. One of the popular topics related to this is the calendar effect, where the researcher tries to find out whether the information in the calendar can generate abnormal returns, compared to the market. The scope of the calendar effect is the weekday effect, January effect, and other special events related to the calendar effect.

The weekday effect was first studied by Fama (1965), who found abnormalities during trading days in the Dow-Jones Industrial Average from January, 1956 to April, 1958.His research disseminated abnormalities in variance, and the hypothesis was that the variance on a Monday would be three times higher than that on any other day, since it would sum up the variability of information during non-trading days - Saturday and Sunday. This finding was interesting because the variance's return on Mondays was $20 \%$ higher than on any other day - later on, the abnormality always happened on Monday, and it became known as the Monday effect.

Many research papers have followed Fama's (1965) ideas to find any abnormality in a trading day. One of the initial followers was French (1980), who examined the abnormality in the mean level instead of the variance level using the S\&P 500's dataset. French's study revealed that the returns on Mondays were less than on any other trading day. Furthermore, the study by Gibbons and Hess confirmed the findings of French (1980) that Monday's returns were the lowest compared to those on the other trading days. In contrast, the returns on Wednesdays and Fridays were the highest.

Rogalski (1984) continued the work using the Dow Jones Industrial Average Index (DJIA) and added a more detailed examination. Instead of studying the close-to-close price (Friday close to Monday close price) as done by previous researchers, he differentiated between the nontrading days, which refers to the Friday close to Monday open and the trading day, which refers to the Monday open to Monday close. Rogalski (1984) found that what contributed to the low return on a Monday was the non-trading day portion, while the trading portion on Monday is as normal as on any other trading day. This split of trading and non-trading days inspired Smirlock and Stark (1986) to do a more detailed analysis. They examined the day-of-the-weekeffect using an hourly analysis, and also split the time frame into three sub-periods (1963 to 1968 , 1968 to 1974 , and 1974 to 1983 ). They found that the hourly Monday return was indeed lower than that on any other day, but only before 1974 . After 1974 there has been no difference between the hourly return of Monday compared to the other trading days.

The research into the Monday effect later became very popular in other countries. Jaffe and Westerfield (1985) examined a similar topic using datasets from the US, Canada, the UK, Japan, and Australia, and they empirically found that the results from the US, Canada, and the UK were the same as those from the previous studies: the lowest returns were on Mondays, but in Japan and Australia the lowest returns were 
on Tuesdays. Condoyani (1987) extended the international day-of-the-week-effect to more countries by adding France and Singapore to the sample. Consistent with Jaffe and Westerfield (1985), in Canada, the effect was found on Mondays, while in Australia, France, Singapore, Japan, and the UK, the effect was seen on Tuesdays.

From previous research papers, the international results of the Monday effect have diverged, since some countries have different weekday effect anomalies. Then, the question is: Is the weekday anomaly just a statistical artifact and not consistent with the asset pricing theory? Studies by Smirlock and Stack (1986), Mehdian and Perry (2001), and Kohers et al. (2004) answer this question; they found that the result of the Monday effect reduces over time. Even Kohers et al. (2004) stated that the effect disappears over time, especially in developed markets. After 1980 the effect fades away, meaning that the markets were getting more efficient.

\section{Indexes in Indonesia}

The capital market in Indonesia has unique characteristics compared to the other developing countries in the Southeast Asia region. These characteristics include the stock index being based on the performance of individual shares. There are two main indexes, namely LQ 45, and Kompas 100, and one composite share price index, JKSE. Each index has certain provisions that are regulated by the regulator.

The first index, LQ 45, is an index consisting of 45 individual stocks that have the following characteristics: Firstly, the individual stock must have good financial conditions, the prospect of growth, a high transaction value and frequency. Secondly, the stocks have been included in the top 60 companies, with the largest market capitalization in the last 12 months. Lastly, the stocks have been included in the top 60 companies with the highest transaction value on a regular market over the last 12 months.

The second index is the Kompas 100, consisting of 100 companies with good fundamental performance, high liquidity, and large market capitalization in Indonesia. But, in general, the performance of companies listed on the Kompas 100 index is below the LQ 45 index. As a consequence, if a company is expected to have high performance but is not among the top companies for 12 consecutive months, then the company will be listed on the Kompas 100 index. The third index is a composite index in Indonesia known as the JKSE. All shares listed on the Indonesian capital market, which consists of speculative and non-speculative shares are in this index. Therefore, based on the characteristics of the indexes in Indonesia, in the form of classifying stock performance, we can make an index for speculative stocks with this assumption.

\section{HYPOTHESES AND RESEARCH METHOD}

In this section, we explain the data source used, the method to decompose the return of the index into speculative, less speculative, and non speculative stock index returns, and also the regression model using a dummy variable to get the evidence of the presence of the day-of-theweek effect.

\section{The Model of the Day-of-Week Effect}

We used the daily returns data from January 2000 to July 2019 from the three main indexes in Indonesia, namely; Jakarta Stock Exchange Composite index (JKSE), the LQ45 index, and the Compass 100 index. JKSE represents the performance of all types of stock traded on the Indonesian stock exchange. The LQ45 index represents the 45 most liquid stocks on the 
market, and the Kompas 100 index represents the 100 most liquid index in the market. Daily returns are calculated using the continuously compounded method with the natural logarithmic first difference of the closing price:

$$
r_{t}=\ln P_{t}-\ln P_{t-1}
$$

Where Pt is the closing stock price of each index at time t. Financial data have a stylized fact that there is the possibility of serial correlation and heteroscedasticity. To overcome this, the study used the standard Ordinary Least Square methodology by assuming the data was non-normal and volatility clustering occurred. Next, we added one lag value from the daily return into the regression model along with five dummy variables to measure the parameters of each week-day. Here is the regression model:

$$
\mathrm{r}_{\mathrm{t}}=\alpha+\gamma \mathrm{r}_{\mathrm{t}-1}+\sum_{j=2}^{5} \beta j \text { Day }+\varepsilon \mathrm{t}
$$

Where rt is the daily return of each index, $\alpha$ is the constant term, and Monday is the base condition of the dummy variable. Meanwhile, to control volatility clustering, this study used the GARCH (p,q) model by incorporating weekday dummies into the conditional variance equation with the following models in Equation 3. The two models above were joint estimation processes, which mean they were estimated simultaneously. The advantage of the two models above is that they can see the weekdays effect that occurs at the mean level and at the variance level.

$$
\begin{gathered}
\sigma^{2}=\eta+\lambda(\mathrm{L}) \omega^{2}{ }_{\mathrm{t}}+\theta(\mathrm{L}) \sigma_{\mathrm{t}-1}^{2}+ \\
\sum_{j=2}^{5} \beta j D a y
\end{gathered}
$$

\section{Speculative vs. Non-Speculative Decomposition}

We identified the non-speculative index return (NS) as the return of the stocks on the most liquid index on the Indonesian stock market. We used the LQ45 as a proxy for the nonspeculative index's return because the index lists the 45 most liquid stocks in Indonesia. Below is the formula to calculate the return of the NS index returns:

$$
N S_{t}=\left(\frac{L Q 45_{t}}{L Q 45_{t-1}}\right)-1
$$

In preparing the stocks included in the speculative index, first, we defined the speculative stocks. Speculative stocks are stocks that are not included in the LQ45 index. We divided all of the stocks that were not included into two groups, so we have two speculative index groups. To form the first group's speculative stock index, we used the Kompas 100 index, which contains the 100 best stocks on the Indonesian stock market. The first speculative stock index had stocks that were not included in the LQ45 index but were included in the Kompas 100 index. As for the second group's speculative stock index, we included all the stocks that were not included in the Kompas 100 index. Therefore, the speculative stocks in the first group had a lower level of speculation than the second group. We called the first group's speculative stock index $\mathrm{S} 1$, and for the second group it was S2. We used the following formula to estimate S1's returns:

$$
\begin{aligned}
& {\left[\left(\text { Ret }_{\text {Kompas 0ot }} * \text { Kompas 00Vol. }\right)-\right.} \\
& S 1_{t}=\frac{\left.\left(\operatorname{Ret}_{L Q 45 t} * L Q 45 \mathrm{Vol} .\right)\right]}{(\text { Kompas } 00 \text { Vol. }-L Q 45 \mathrm{Vol} .)}
\end{aligned}
$$

Where RetKompas $100_{t}$ is the return of the Kompas 100 index, RetLQ45 ${ }_{t}$ is the return of the LQ45 index, LQ45 $\mathrm{Vol}_{\mathrm{t}}$ is the volume of LQ45 index, and the Kompas 100 Vol $_{t}$ is the volume of Kompas100 index. We used volume data from the Kompas 100 index and LQ45 index as proxies to estimate the weight component in Equation (5).

For S2's returns, we used the returns of the Jakarta Composite Index (JKSE) as a benchmark 
because the index contained all the stocks available on the Indonesian stock market. Therefore, S2's stocks are all the stocks that were included on the Jakarta Composite Index, but excluded from the LQ45 and Kompas 100 indexes. We used the following equation to estimate S2's returns:

$$
\begin{aligned}
& {\left[\left(\operatorname{Ret}_{\text {IHSG }} * \text { IHSGVol. }\right)-\right.} \\
& S 1_{t}=\frac{\left.\left(\text { Ret }_{\text {Kompas 00t }} * \text { Kompas 00Vol } .\right)\right]}{(\text { IHSGVol. }- \text { Kompas 00Vol } .)}
\end{aligned}
$$

Where RetIHSG $G_{t}$ is the return of the Jakarta Composite Index, and IHSGVol $\mathrm{l}_{\mathrm{t}}$ is the volume of the Jakarta Composite Index.

We defined the traditional Monday effect accusing the returns on Mondays to be lower than on any other trading day of the week. There was also the possibility of other weekday effects (such as the Wednesday effect). Therefore we used 2-tailed testing using a notation $B_{j}(1=$ Monday, 2 = Tuesday, etc.) following Doyle and Chen (2009). The null hypothesis was:

$$
\begin{aligned}
\mathrm{H}_{0}= & B_{1}+B_{2}+B_{3}+B_{4}+B_{5}=0 \text { (null for Monday } \\
& \text { effect) } \\
\mathrm{H}_{1}= & B_{1}+B_{2}+B_{3}+B_{4}+B_{5} \neq 0 \text { (for Monday or } \\
& \text { weekday effect) }
\end{aligned}
$$

\section{RESULTS AND DISCUSSIONS}

\section{Descriptive Statistics}

Table 1 outlines the descriptive statistics of the index returns before their decomposition into the new speculative index.

Table 1 illustrates the highest average return from January 2000 to July 2019 was from the IHSG with a value of $0.0422 \%$ while the average return for other indexes was similar, at around $0.037 \%$. The total risk measured by the standard deviation showed the LQ 45 index was the riskiest, with a value of $1.51 \%$ compared to the Kompas 100 index, which was $0.10 \%$ lower. The risk in the LQ 45 index may have been caused by systematic risk's composition, with a beta value of 1.19 .

Table 1. Index return before decomposition

\begin{tabular}{cccc}
\hline & LQ45 & K100 & IHSG \\
\hline Mean & $0.0373 \%$ & $0.0377 \%$ & $0.0422 \%$ \\
Standard Deviation & $1.51 \%$ & $1.44 \%$ & $1.26 \%$ \\
Min. & $10.30 \%$ & $9.13 \%$ & $7.92 \%$ \\
Max. & $-11.86 \%$ & $-11.16 \%$ & $-10.38 \%$ \\
Beta & 1.19 & 1.13 & 1.00 \\
\hline
\end{tabular}

Figure 1 reflects an upward and downward trend in the three indexes in Indonesia. Overall, stock price trends in all three indices rose with the highest share prices in 2018, and the lowest share prices were seen from 2008 to 2009 . In 2008 and 2009, there was a global crisis, better known as the subprime mortgage crisis in America, resulting in a decline in share prices in Indonesia. Two indexes, the Kompas 100 and LQ 45 experienced relatively similar price movements for the entire observation period. Besides, these indexes have a pattern of movement that is almost the same as the IHSG, where there was a sharp decline in 2008 and 2016, and an increasing pattern in 2013 and 2017.

Once we had done the decomposition process for the three major indexes in the capital market, we got three indexes consisting of speculative, less speculative, and non-speculative indexes. Recalling that a speculative index is a stock price index consisting of stocks in Indonesia that have the characteristics of a small trading volume, volatility, unprofitable, nondividend paying, lottery-like, potentially close to distress, and having extreme growth, so that shares like this make it difficult to judge them properly. Table 2 illustrates the descriptive statistics of the three indexes. On average, the highest return was from the speculative stock price index, while the lowest return was from the non-speculative index. Interestingly, the lowest 
standard deviation was in the speculative index, with a value of $0.84 \%$ compared to the other three indexes. This seems to contrast with the risk-return trade-off in asset pricing, but this might be because the speculative index in Indonesia consists of less attractive stocks; hence investors rarely deal in these stocks. In Table 3, we segregate the sample period into during the crisis and after the crisis, and we find the consistent pattern of the speculative index has the highest return and the lowest risk during the two periods.

Table 2. Descriptive Statistics Index NonSpeculative (NS), Less Speculative (S1), and Speculative (S2)

\begin{tabular}{cccc}
\hline & NS & S1 & S2 \\
\hline Mean & $0.0373 \%$ & $0.0374 \%$ & $0.0545 \%$ \\
Standard Deviation & $1.51 \%$ & $1.23 \%$ & $0.84 \%$ \\
Min. & $10.30 \%$ & $8.10 \%$ & $4.70 \%$ \\
Max. & $-11.86 \%$ & $-7.79 \%$ & $-8.72 \%$ \\
Beta & 1.19 & 0.80 & 0.57 \\
\hline
\end{tabular}

Figure 2 depicts the movement of the three indexes resulting from the decomposition process into speculative stocks. Based on the figure above, it can be seen that the price movements (trends) in the non-speculative stocks were relatively stable compared to the less speculative and speculative stocks. The speculative index experienced an increase in stock pricesdue to price movements from 2009 to 2012 , and reached a peak in 2018. On the other hand, the non speculative index experienced a decline in 2018.

Table 3. Descriptive Statistics Decomposition Index During and After the Crisis Period

\begin{tabular}{lccc}
\hline \multicolumn{4}{c}{ Crisis 2007-2010 } \\
\hline Mean & NS & S1 & S2 \\
Median & $0.05 \%$ & $0.07 \%$ & $0.07 \%$ \\
Maximum & $10.30 \%$ & $8.10 \%$ & $4.70 \%$ \\
Minimum & $-11.86 \%$ & $-7.79 \%$ & $-8.72 \%$ \\
Std. Dev. & $2.16 \%$ & $1.66 \%$ & $1.28 \%$ \\
\hline \multicolumn{4}{c}{ After Crisis $\mathbf{( 2 0 1 0 - 2 0 1 9 )}$} \\
\hline Mean & NS & $\mathrm{S} 1$ & $\mathrm{~S} 2$ \\
Median & $0.03 \%$ & $0.03 \%$ & $0.05 \%$ \\
Maximum & $6.19 \%$ & $0.00 \%$ & $0.04 \%$ \\
Minimum & $-10.13 \%$ & $-7.12 \%$ & $-6.15 \%$ \\
Std. Dev. & $1.22 \%$ & $1.05 \%$ & $0.62 \%$ \\
\hline
\end{tabular}

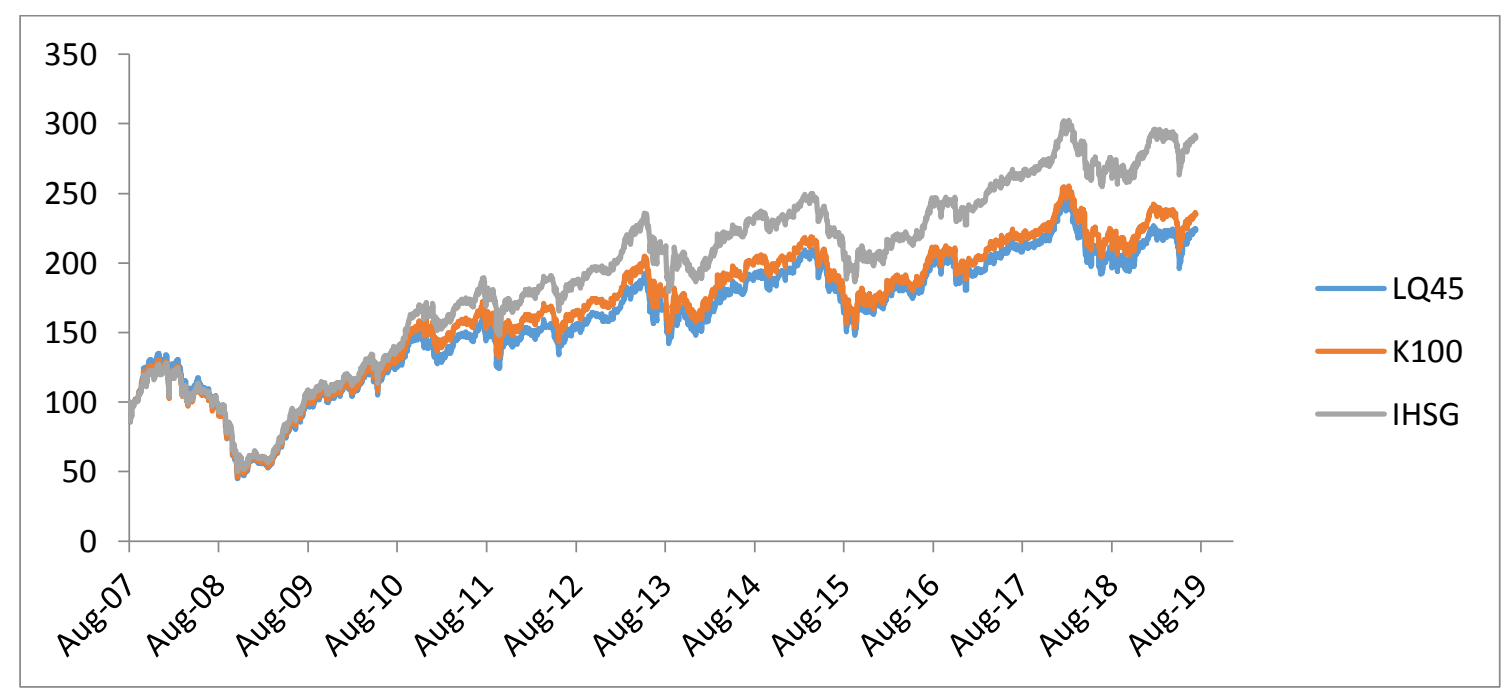

Figure 1. Trend index before decomposition 


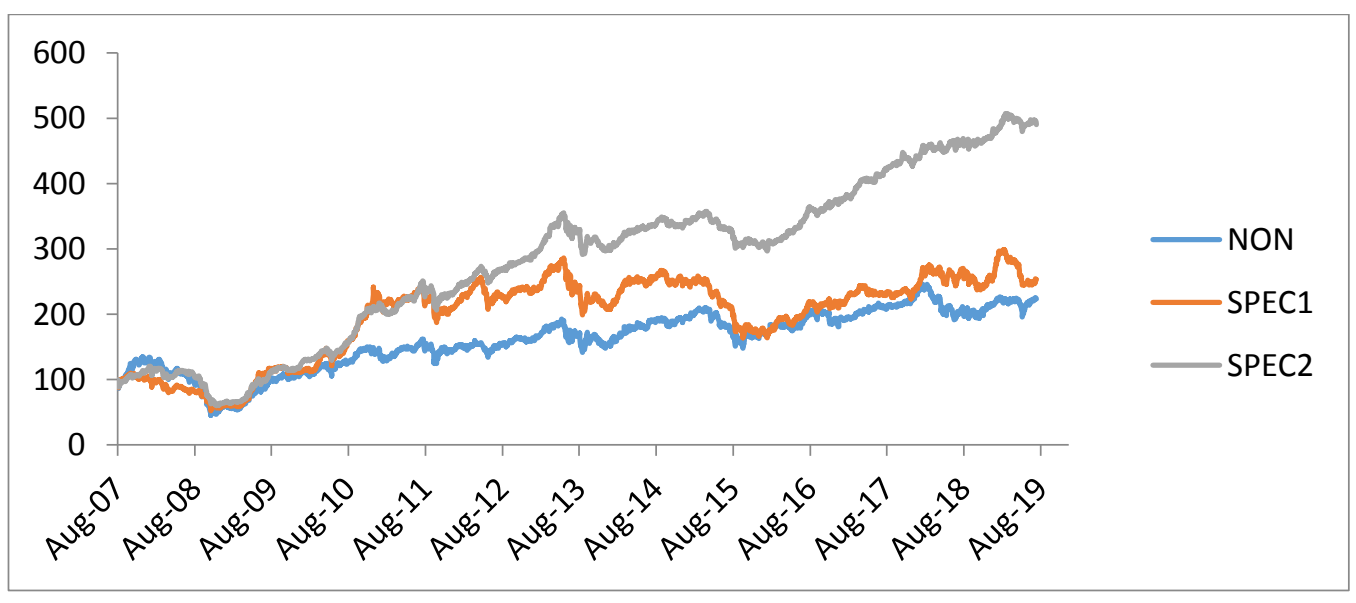

Figure 2. Trend index after decomposition

\section{Empirical Analysis and Findings}

In this section, we investigate the day-of-theweek effect on the three indexes (speculative, less speculative, and non-speculative) using a dummy regression for the mean equation, and to control the heteroscedasticity we use the GARCH model. We only show the regression result from the mean level to save space. However, the full estimation can be shown by request.

Table 4 provides the estimation results for the three indexes from January to July 2019. Overall, we found that the weekday effect anomaly does exist in Indonesia. The three indexes experienced a similar pattern namely, on
Wednesdays, the highest and most significant average returns with the highest average returns are from the less speculative stocks with a value at $0.19 \%$, as opposed to the lowest return from the speculative indexes at about $0.14 \%$. The average return value then decreased gradually to reach a negative value on Mondays, while the less speculative index was the only index to have a significant negative return on that day. On a specific day such as Friday, the speculativeS2 index experienced the highest positive and significant returns of $0.09 \%$ compared to less speculative S1index and the non-speculative (NS) at $0.08 \%$ and $0.05 \%$ consecutively.

Table 4. Estimation Result Mean Level Regression Full Sample Period

\begin{tabular}{|c|c|c|c|c|c|c|}
\hline Day & NS. & & S1 & & $\mathbf{S 2}$ & \\
\hline Monday & $\begin{array}{c}-0.0888 \% \\
(0.203)\end{array}$ & & $\begin{array}{c}-0.1733 \% \\
(2.874)\end{array}$ & $* * *$ & $\begin{array}{c}-0.0492 \% \\
(1.042)\end{array}$ & \\
\hline Tuesday & $\begin{array}{c}0.0254 \% \\
(0.357)\end{array}$ & & $\begin{array}{c}-0.0016 \% \\
(0.479)\end{array}$ & & $\begin{array}{c}0.0193 \% \\
(0.564)\end{array}$ & \\
\hline Wednesday & $\begin{array}{c}0.1802 \% \\
(3.127)\end{array}$ & $* * *$ & $\begin{array}{c}0.1941 \% \\
(4.501)\end{array}$ & $* * *$ & $\begin{array}{c}0.1460 \% \\
(3.571)\end{array}$ & $* * *$ \\
\hline Thursday & $\begin{array}{c}0.0172 \% \\
(1.009)\end{array}$ & & $\begin{array}{c}0.0856 \% \\
(1.982)\end{array}$ & $*$ & $\begin{array}{c}0.0659 \% \\
(2.493)\end{array}$ & $* *$ \\
\hline Friday & $\begin{array}{c}0.0526 \% \\
(0.305)\end{array}$ & & $\begin{array}{c}0.0825 \% \\
(1.194)\end{array}$ & $*$ & $\begin{array}{c}0.0907 \% \\
(3.007)\end{array}$ & $* * *$ \\
\hline R-Square & 0.004 & & 0.011 & & 0.010 & \\
\hline F-Stat & 2.402 & & 6.746 & & 6.545 & \\
\hline Sig. & 0.035 & & 0.000 & & 0.000 & \\
\hline
\end{tabular}

Notes t-statistics is reported in parentheses.

$* * *$ Significant at $1 \%$ level; ** Significant at $5 \%$ level; * Significant at $1 \%$ level 
To answer the second question, as well as to check the consistency of our results, we conducted a robustness check by splitting the estimation period into during and after the global financial crisis (GFC) in Table 5. During the GFC period, we found a significant Wednesday effect for all the indexes (NS, S1, and S2)and the highest return, of $0.25 \%$ for the non-speculative and speculative indexes. For the speculative index, we found the return on Tuesdays was the lowest at $0.16 \%$ and significant at $95 \%$. After the GFC period, we found consistent results for the Wednesday effect in all the indexes. For the S2 index, we found that all the days were significant, compared to the other indexes, where the lowest returns were on Mondays at $0.01 \%$ and the highest return was on Wednesdays at $0.01 \%$.

Our findings support the mood hypothesis from Birru (2018) and Chiah and Zhong (2019) that investors' moods tend to rise on Fridays and fall on Mondays. Investors who are in a good mood tend to buy speculative stocks on a Friday, causing the returns to be positive and significant. Investors make these transactions only due to their psychological impulses, without considering other relevant information such as the company's fundamentals.

Table 5. Estimation result for the mean level regression during and after crisis period

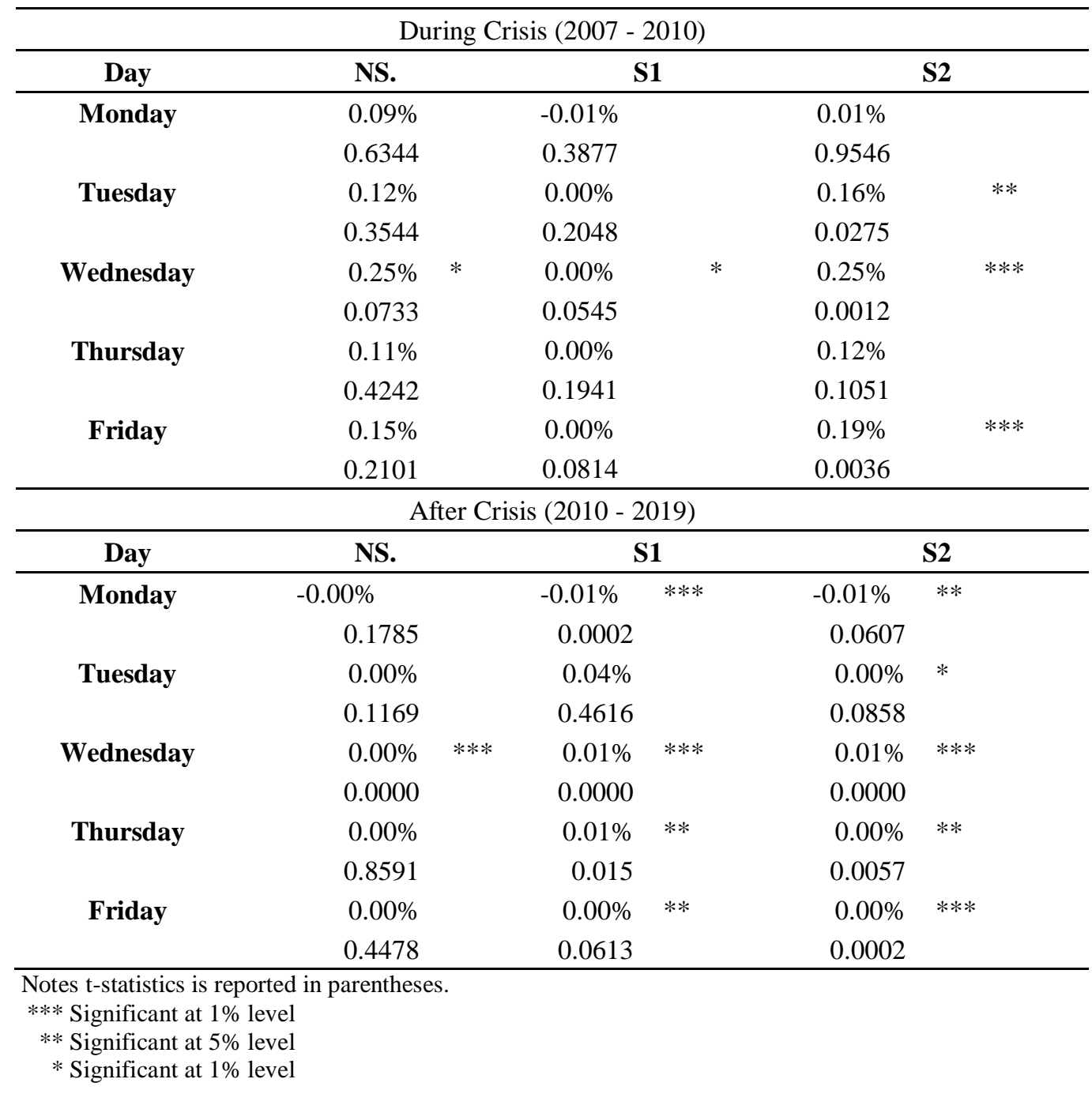


Empirically, we found that the highest investor mood in Indonesia is on Wednesdays and gradually decreases to the lowest level on Mondays. The high investor mood can be seen from the highest average return estimation results in Table 3. Interestingly, we empirically found that the psychological mood of the investors' moods was more significant in the less speculative index, which tended to be more stable in performance than the speculative index. We may argue that investors in Indonesia are not completely irrational by using their mood when trading. Rationality and psychology can play a role for Indonesian investors since they are more active in trading less speculative stocks when their mood is good, to avoid higher risk. Our findings are the same as the findings from Boubaker et al. (2017) and Anwar and Mulyadi (2012), who examined the weekday effects of the global major capital markets. Their results show that there is a positive significant Wednesday return.

The estimation results from our previous findings might have been influenced by global conditions such as the subprime mortgage crisis, or the up and downturn in macroeconomic conditions, both of which affected the fundamental value of stocks. Therefore we divided the estimation period according to the method used by Zhang, Lai, and Lin (2017) with three periods, namely the high upside period, the normal period, and the low upside period based on the rise and fall of the stock index.

Table 6 shows the results of the estimated weekday effects with three time periods. The highest average return consistently occurred on Wednesdays for the whole index. Meanwhile, the speculative index was very sensitive to the division of this period, where during the upside period, the return value became positive and significant for the whole of every day (except Mondays), with the highest returns on Wednesdays at $0.28 \%$ and the lowest returns on Mondays at $0.14 \%$. In contrast, during the normal period, the speculative index experienced the highest returns on Wednesdays and the poorest returns on Mondays.

Table 6. Estimation result mean level in three periods

\begin{tabular}{|c|c|c|c|c|c|c|c|c|c|}
\hline \multirow{2}{*}{ Day } & \multicolumn{3}{|c|}{ High Upside Period (2009 _ 2012) } & \multicolumn{3}{|c|}{ Normal period (2012 _ 2015) } & \multicolumn{3}{|c|}{ Low Upside Period (2016 _ 2019) } \\
\hline & NON SPEC. & SPEC. 1 & SPEC. 2 & NON SPEC. & SPEC. 1 & SPEC. 2 & NON SPEC. & SPEC. 1 & SPEC. 2 \\
\hline \multirow[t]{2}{*}{ Monday } & $-0.0462 \%$ & $-0.1391 \%$ & $0.0149 \%$ & $-0.2252 \% * *$ & $-0.2807 \% * * *$ & $-0.1546 \% * * *$ & $0.0438 \%$ & $-0.0863 \%$ & $0.0269 \%$ \\
\hline & 1.644 & 1.129 & 0.914 & 2.039 & 3.001 & 5.002 & 1.557 & 1.187 & 1.391 \\
\hline \multirow[t]{2}{*}{ Tuesday } & $0.1156 \%$ & $0.1927 \% * *$ & $0.1634 \% * *$ & $0.0698 \%$ & $-0.1234 \%$ & $-0.0005 \%$ & $0.0193 \%$ & $-0.0719 \%$ & $-0.0111 \%$ \\
\hline & 1.249 & 4.036 & 2.010 & 1.521 & 1.155 & 0.992 & 1.795 & 1.271 & 1.724 \\
\hline \multirow[t]{2}{*}{ Wednesday } & $0.3469 \% * * *$ & $0.3648 \% * * *$ & $0.2808 \% * * *$ & $0.1851 \% *$ & $0.1107 \%$ & $0.1185 \% * *$ & $0.0773 \%$ & $0.2241 \% * * *$ & $0.0947 \% * * *$ \\
\hline & 3.001 & 4.000 & 5.000 & 1.989 & 1.202 & 2.016 & 1.301 & 3.648 & 3.003 \\
\hline \multirow[t]{2}{*}{ Thursday } & $-0.0138 \%$ & $0.1282 \%$ & $0.1454 \% * *$ & $0.0564 \%$ & $0.0845 \%$ & $0.0194 \%$ & $0.0293 \%$ & $0.1125 \% *$ & $0.0630 \% * *$ \\
\hline & 0.890 & 1.161 & 2.022 & 1.604 & 1.330 & 0.916 & 1.695 & 1.986 & 2.045 \\
\hline \multirow[t]{2}{*}{ Friday } & $0.1313 \%$ & $0.1486 \%$ & $0.1362 \%$ ** & $0.0066 \%$ & $0.0708 \%$ & $0.0686 \%$ & $-0.0037 \%$ & $0.0296 \%$ & $0.0770 \% * *$ \\
\hline & 1.190 & 1.105 & 2.032 & 0.952 & 1.416 & 1.163 & 0.961 & 1.650 & 2.014 \\
\hline R-Square & 0.014 & 0.025 & 0.034 & 0.010 & 0.020 & 0.022 & 0.002 & 0.019 & 0.021 \\
\hline F-Stat & $3.049 \quad * * *$ & 5.432 & $7.214 \quad * * *$ & 1.567 & 3.134 & 3.570 & 0.329 & $3.567 \quad * * *$ & 4.015 \\
\hline Sig. & 0.010 & 0.000 & 0.000 & 0.167 & 0.008 & 0.003 & 0.896 & 0.003 & 0.001 \\
\hline
\end{tabular}

Notes t-statistics is reported in parentheses.

$* * *$ Significant at $1 \%$ level

** Significant at $5 \%$ level

* Significant at $1 \%$ level 
Using these three periods, we show that the mood hypothesis from Birru (2018) and Chiah and Zhong (2019) is supported in Indonesia. We may argue that during normal conditions, investors tend to only use the pure behavioral mood to trade on Wednesdays when the mood is good for speculative stocks, because they are considered to have good prospects. This happens since the investors experience indifference between gaining the return and avoid risk. Conversely, on Mondays, investors tend to sell speculative stocks when the mood is bad. When the index conditions are good, and the stock price rises significantly (high-upside period), and when the stock price only rises steadily (low upside period), investors tend to be more rational.

\section{CONCLUSION}

Research related to the anomaly of the day-ofthe-week effect, which began in 1930 with a study by Kelly and is still ongoing, as shown by the recent studies from Richards and Willows (2019), found that the returns on Mondays are always negative compared to other days, so this phenomenon is called the Monday effect anomaly. This anomaly can generally only be explained by the existence of persistent seasonal ties in the capital market.

Birru (2018) and Chiah and Zhong (2019) suggested the hypothesis that the Monday effect could be influenced by the psychological bias from investors. They argued that the investor mood hypothesis is a condition where an investor's mood will rise on a Friday and fall on a Monday. The consequence of this hypothesis is that investors will buy stocks with good prospects when the mood is good and sell them when the mood is bad.

The motivation for our research was to examine the mood behavior of investors using a highly mispriced capital market as a sample
(Indonesia). Instead of manually listing individual speculative stocks, we postulated a new method to decompose indexes into speculative, less speculative, and non-speculative indexes,

We empirically find that the mood of the investors is highest on Wednesdays, while the mood is lowest on Mondays. Using the full sample period, we reveal that less speculative stocks are supported by the behavior of the mood investor hypothesis. To get clearer results, we divided our sample period into three testing periods (upside, normal, and low side). We found that the behavior mood hypothesis is supported only in normal periods when investors tend to be irrational and use their good mood to trade in speculative stocks on a Wednesday and sell them on a Monday.

Besides, we find that investors in Indonesia are not completely irrational by using their mood when trading in the high-upside and low-upside periods. Rationality and psychology play a role for Indonesian investors since they are more active in trading less speculative stocks to avoid greater risk and earn a positive return in those periods when the mood is good.

The research's implication for investors is that they should buy stocks on Mondays when the prices are very low and sell on Wednesdays when the average investors are in a good mood to buy shares, which causes the stock prices to rise significantly. In this study, we have a limitation, in that the weekday effect is static (does not vary overtime). However, in the real case, investors have mood swings that result in dynamic weekday effects (wandering effects). For future research, we suggest using the dynamic weekday effect model to study the psychological mood of the investors.

\section{REFERENCES}

Ali, F., \& Ülkü, N. (2018). Monday Effect in the RMW and the Short-Term Reversal Factors. 
International Review of Finance, 19(3), 681-691.

Asness, C. S., Frazzini, A., \& Pedersen, L. H. (2019). Quality minus junk. Review of Accounting Studies, 24(1), 34-112.

Baker, M., \& Wurgler, J. (2006). Investor sentiment and the cross-section of stock returns. The journal of Finance, 61(4), 1645-1680.

Bagozzi, R. P., Gopinath, M., \& Nyer, P. U. (1999). The role of emotions in marketing. Journal of the academy of marketing science, 27(2), 184-206.

Birru, J. (2018). Day of the week and the crosssection of returns. Journal of financial economics, 130(1), 182-214.

Chiah, M., \& Zhong, A. (2019). Day-of-theweek effect in anomaly returns: International evidence. Economics Letters, 182, 90-92.

Condoyani, L., and J. O'Hanlon (1987). Day of the week effect on stock returns: the international evidence. Journal of Business Finance and Accounting, 14, $159-174$.

Doyle, J. R., \& Chen, C. H. (2009). The wandering weekday effect in major stock markets. Journal of Banking \& Finance, 33(8), 1388-1399.

Fama, E. F. (1970). Efficient capital markets: A review of theory and empirical work. The journal of Finance, 25(2), 383-417.

French, K. (1980). Stock returns and the weekend effect.Journal of Financial Economics, volume 8, issue 1, 55-69.

G. Kohers, N. Kohers, V. Pandey \& T. Kohers (2004). The disappearing day-of-the-week effect in the world's largest equity markets. Applied Economics Letters. 11:3, 167-171, DOI: $10.1080 / 1350485042000203797$.
Jacobs, H. (2016). Market maturity and mispricing. Journal of Financial Economics, 122(2), 270-287.

Jaffe, J., \& Westerfield R., (1985). The weekend effect in common stock returns: the international evidence. The Journal of Finance. Vol. 40, No.2, pp. 433-454.

Kelly, F. (1930). Why you win or lose: the psychology of speculation. Boston: Houghton Mifflin.

Mehdian, S. \& Perry M.J. (2001). The reversal of the Monday effect: new evidence from US equity markets.Journal of Business Finance and Accounting, 28(7).

Wright, F. W., \& Bower, G.H (1992). Mood effects on subjective probability assessment. Organizational Behavior and Human Decision Processes, 52, 276-291.

Richards, D. W., \& Willows, G. D. (2019). Monday mornings: Individual investor trading on days of the week and times within a day. Journal of Behavioral and Experimental Finance, 22, 105-115.

Rogalski, R. J. (1984). New findings regarding day-of-the-week returns over trading and non-trading periods: a note. The Journal of Finance, Volume 39, Issue 5.

Smirlock, M., \& Starks, L. (1986). Day-of-theweek and intraday effects in stock returns. Journal of Finance Economics, Volume 17, Issue 1, 197-210.

Stambaugh, R. F., Yu, J., \& Yuan, Y. (2015). Arbitrage asymmetry and the idiosyncratic volatility puzzle. The Journal of Finance, 70(5), 1903-1948.

Zhang, J., Lai, Y., \& Lin, J. (2017). The day-ofthe-week effects of stock markets in different countries. Finance Research Letters, 20, 47-62. 